\title{
ABNORMALITY IN SERUM CALCIUM, PHOSPHATE AND VITAMIN-D LEVELS IN CHRONIC RENAL FAILURE PATIENTS: A CASE CONTROL STUDY IN THE EASTERN INDIAN POPULATION
}

\section{Dr Chinmoy Ghosh}

\section{Dr. Sandip} Chakraborty

\section{Dr Änab Ghosh}

\section{Dr Sayantan Dasgupta*}

Assistant Professor, Department of Biochemistry, NRS Medical College, Kolkata 14.

Associate Professor, Department of Biochemistry, NRS Medical College, Kolkata 14.

Demonstrator. Department of Anatomy, Deben Mahata Government Medical College and Hospital, Purulia - 723147.

Associate Professor, Department of Biochemistry, North Bengal Medical College, Susrutanagar, Darjeeling- 734012. *Corresponding Author

ABSTRACT Chronic renal failure (CRF) is one of the most important health problems in our population. From the early stages of the disease progression, the activation of Vitamin D in kidney is affected, resulting in abnormality in the regulation of calcium and phosphate homeostasis in the blood. In the present study, 30 Chronic Renal Failure patients visiting Nephrology OPD and 30 age and sex matched volunteers were studied. Serum levels of Urea, Creatinine, Calcium, Phosphate and Vitamin D were measured in the study participants. The data after statistical analysis showed significantly higher levels of Phophate and significantly lower levels of Calcium and Vitamin D in the CRF patients in comparison to healthy control subjects. Phosphate and Vitamin D also shows significant correlation with serum creatinine levels in the CRF patients. The present study confirms the abnormality in Calcium-Phosphorus metabolism as a complication of CRF in our population, and highlights the importance of regularly measuring these parameters in CRF patients and possible need of taking corrective measures in this regard.

KEYWORDS : Chronic Renal Failure, Serum Calcium, Serum Phophate, Serum Vitamin D

INTRODUCTION

Chronic renal disease is an internationally recognized public health problem affecting $5-10 \%$ of the world population ${ }^{[1,2]}$. Disturbances of calcium-phosphate (Ca-P) and vitamin D metabolism in chronic renal failure (CRF) play a key role in the development of secondary hyperparathyroidism. Hyperphosphataemia and increased calcium a phosphate product have been directly linked to increased mortality in a large number of haemodialysis patients. Calcification of coronary plaques and myocardial tissue, as well as diffuse myocardial fibrosis, is common pathologic findings in uremic hearts ${ }^{[3,4]}$. The data clearly point to controlling hyperphosphataemia, 'a silent killer of patients with renal failure ${ }^{[5]}$. Normal calcium and phosphate homeostasis is interrupted beginning early in the course of chronic kidney disease (CKD). Rising FGF-23 levels suppress renal production of 1,25-dihydroxyvitamin $\mathrm{D}$, which reduces klotho expression. Sensing a threat to the ionized calcium concentration due to less efficient gastrointestinal calcium absorption, the parathyroid glands increase PTH secretion, which is augmented by release of the glands from feedback inhibition by reduced 1,25-dihydroxyvitamin D levels. Recognition that elevated levels of FGF-23, PTH, and phosphate and low levels of 1,25-dihydroxyvitamin D and calcium are associated with adverse clinical outcomes has stimulated interest in earlier treatment of disordered mineral metabolism in CKD. PTH rises in CKD as a secondary response to calcium depletion and that FGF-23 rises as a secondary response to phosphate retention, but there are limited data on calcium and phosphate balance in CKD.

Phosphorus is suggested to increase PTH synthesis at the post a transcriptional level. The parathyroid cells respond to changes in serum phosphorous concentration at the level of gene expression by the same mechanism as that describe for calcium; that is by influencing PTH-mRNA stability. Low phosphorus decreases, where as high phosphorous increases PTH-mRNA stability ${ }^{[6]}$

The control of Hyperphosphataemia in advanced CRI is of utmost importance for 3 main reasons- 1 .

Hyperphosphataemia contributes to the pathogenesis of secondary hyperparathyroidism and its skeletal expression ${ }^{[7]}$. 2. It promotes, together with calcium and vitamin $D$, the formation and deposition of calcium-phosphate crystals in soft tissues, in particular in the vessel wall \& in heart valves ${ }^{[8]}$. 3. There is a direct, independent association between the degree of Hyperphosphataemia and cardiovascular morbidity and mortality in dialysis patients ${ }^{[9]}$.

Recognition that elevated levels of FGF-23, PTH, and phosphate and low levels of 1,25-dihydroxyvitamin D and calcium are associated with adverse clinical outcomes has stimulated interest in earlier treatment of disordered mineral metabolism in CKD with all these issues in mind, in this study we have tried to find out the occurrence of derangement in $\mathrm{Ca}$ metabolism in CKD patients in this part of our country.

\section{METHODS:}

- Study area: The study was done at NIL RATAN SIRCAR MEDICAL COLLEGE and HOSPITAL, in Kolkata in the department of BIOCHEMISTRY.

- Study period: The study conducted from $16^{\text {th }}$ April to $30^{\text {th }}$ June 2016.

- Sample size: Blood samples for 30 patients suffering from CKD and 30 samples were collected as healthy volunteers.

- Sample selection: During my study period diagnosed patient of chronic renal failure attended to Nephrology OPD or admitted in Nephrology IPD of NRS medical collage were included in the study.

- Blood sample were taken after overnight fasting. $3 \mathrm{ml}$ of blood sample were collected using the aseptic measure. The samples were allowed to stand for $\mathrm{lhr}$ and then centrifuged. The serum collected was for calcium, phosphate, vitamin $\mathrm{D}$ and ready for experiment. The samples were stored at $-20^{\circ} \mathrm{C}$ for further use.

- Calcium, phosphate, vitamin D, urea, creatinine, sodium were tested by standardized reagent kits in the department of biochemistry. 
- Estimation of serum calcium by OCPC method

- Estimation of serum phosphate by molybdate UV method

- Estimation of serum 25-oh vitamin D by commercial ELISA kit

- Estimation of serum urea by Berthelot method

- Estimation of serum Creatinine by modified Jaffe Kinetic method

\section{STATISTICĀL ĀNALLYSIS:}

The statistical analysis of the data were done using SPSS version 16 software.

\section{RESULTS:}

Table 1: Comparison of Mean and SD values of various parameters in CRF Patients and control subjects

\begin{tabular}{|l|l|l|}
\hline Parameter & Cases (Mean \pm SD) & Control (Mean \pm SD) \\
\hline Urea & $169 \pm 35.4$ & $69.5 \pm 5.9$ \\
\hline Creatinine & $6.8 \pm 1.04$ & $4.9 \pm 0.26$ \\
\hline Calcium & $6.6 \pm 1.7$ & $9.2 \pm 0.5$ \\
\hline Phosphate & $6.6 \pm 2.4$ & $4.6 \pm 0.47$ \\
\hline Vitamin $\mathrm{D}_{3}$ & $22.1 \pm 6.1$ & $30.4 \pm 7.3$ \\
\hline
\end{tabular}

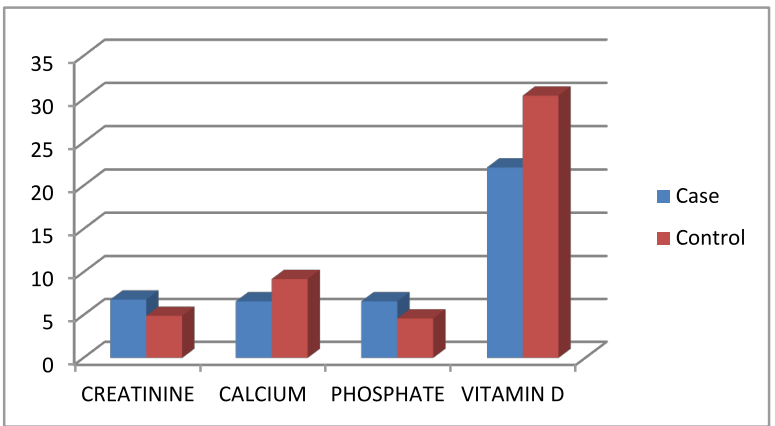

Figure 1: Comparison of Means of various parameters in CRF Patients and control subjects

Table 2: Comparison of Mean by Independent $t$ test \begin{tabular}{|l|l|l|l|l}
\hline Parameter & $t$ Value P Value & Significance Of Difference* \\
\end{tabular}

\begin{tabular}{|l|l|l|l|}
\hline Urea & 11.3 & $<0.001$ & Statistically significant \\
\hline Creatinine & 6.9 & $<0.001$ & Statistically significant \\
\hline Calcium & -8.6 & $<0.001$ & Statistically significant \\
\hline Phosphate & 4.7 & $<0.001$ & Statistically significant \\
\hline Vitamin $\mathrm{D}_{3}$ & -5.4 & $<0.001$ & Statistically significant \\
\hline
\end{tabular}

${ }^{*}$ Statistical significance considered at $95 \%$ confidence interval

Table 3: Correlation of various parameters with Creatinine level in CRF patients.

\begin{tabular}{|l|l|l|l|}
\hline Parameter & $\begin{array}{l}\text { Correlation } \\
\text { coefficient }\end{array}$ & P Value* & $\begin{array}{l}\text { Significance Of } \\
\text { Difference* }\end{array}$ \\
\hline Calcium & -0.211 & 0.191 & Not Significant \\
\hline Phosphate & 0.338 & 0.033 & Statistically significant \\
\hline Vit D3 & -0.386 & 0.014 & Statistically significant \\
\hline
\end{tabular}

${ }^{*}$ Statistical significance considered at $95 \%$ confidence interval

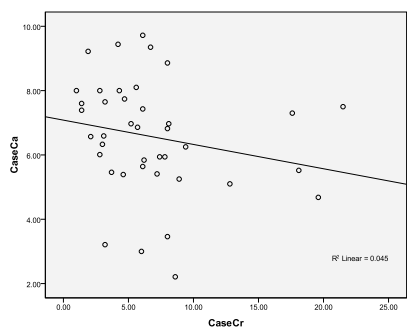

Figure 2: Scatter diagram showing correlation between Serum creatinine and calcium in CRF patients.

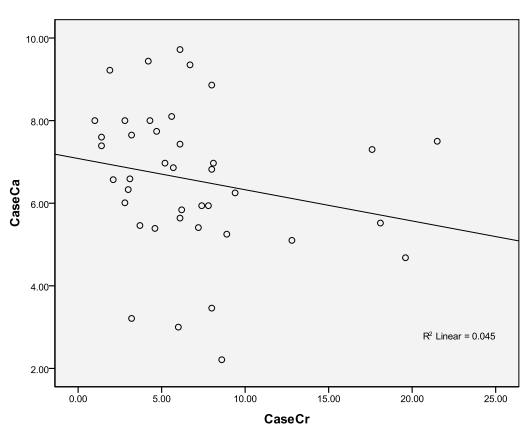

Figure 3: Scatter diagram showing correlation between Serum creatinine and Phosphate values in CRF patients.

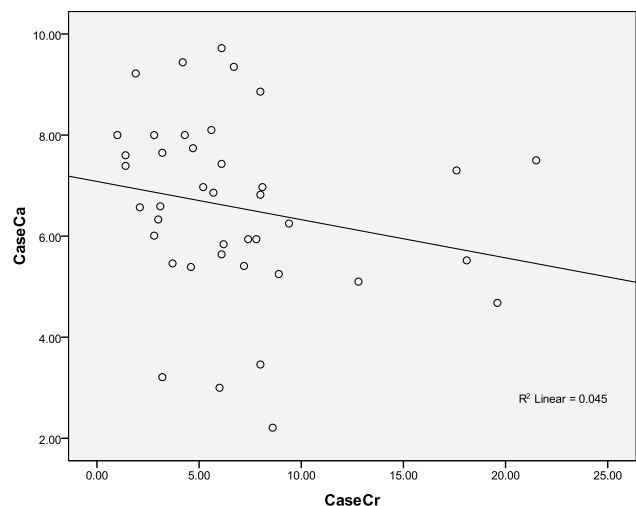

Figure 4: Scatter diagram showing correlation between Serum creatinine and Vit D values in CRF patients.

\section{DISCUSSION:}

The abnormality in the regulation of Calcium and Phosphate metabolism in Chronic Renal Failure Patients is one of the most important complications of the conditions, which then leads to clinic pathological implications that affect the patient further. The present study, done on chronic renal failure patients of eastern India found out that Both serum calcium and serum Vitamin D levels were significantly low, whereas the serum Phosphate levels were significantly higher in the Renal failure patients in comparison to the controls subjects [Table 1,2 and figure 1]. On further analysis, it was also found in the present study, that that both Phosphate and Vitamin D levels were significantly correlated with the serum creatinine level, in the CRF patients, [Table 3, Figure 3,4] signifying that more severity of renal failure, more deranged are these parameters. The serum calcium level in these patients, though showed a negative correlation with the serum creatinine level, the correlation was not found to be statistically significant in the present study [Table 3, Figure 2]

This result is in accordance with similar studies done previously on different group of population. Stevens L et al not only showed presence of abnormality in the calcium and phosphate levels, but also can predict mortality in these patients ${ }^{[10]}$. Block $\mathrm{G}$ et al also has shown in their study direct correlation of Calcium X Phosphate product also increases mortality risk in CRF patients ${ }^{[11}$. The presence of elevated calcium X phosphate product and its long term negative effect is also shown in the study of Egbuna et al ${ }^{[12]}$ and Thongprayoon et $\mathrm{al}^{[13]}$. The biochemical alterations of CKD include elevated fibroblast growth factor-23 (FGF23) and parathyroid hormone (PTH), decreased 1,25dihydroxyvitamin D (1,25D), elevated serum phosphate, and decreased serum calcium ${ }^{[14]}$. Excessive circulating phosphate is excreted by the kidney in response to PTH and fibroblast growth factor-23 (FGF-23) binding to FGF receptor-klotho co-receptor complexes. As part of an intricate set of feedback loops that tightly regulate 
calcium and phosphate homeostasis, both PTH and 1,25dihydroxyvitamin D stimulate FGF-23 secretion, and FGF23 is the primary negative regulator of 1,25dihydroxyvitamin D production. Yasin et al has even shown in their study, that the FGF level in the CRF patients, infact correlates with the Calcium X Phosphate product and it can act as a biomarker for the risk of cardiovascular calcifications in these patients ${ }^{[15]}$.

Phosphorous retention played an important role in the pathogenesis of secondary hyperparathyroidism. Several mechanisms are involved. Phosphorus induces hypocalcaemia and decreases plasma $1,25-(\mathrm{OH})_{2} \mathrm{D}_{3}$ levels by reducing the activity of the renal enzyme 25 hydroxyvitamin $D$ $1 \alpha$ hydroxylase. Phosphorous also stimulates PTH-mRNA synthesis independent of changes in serum calcium and $1,25(\mathrm{OH})_{2} \mathrm{D}_{3}{ }^{[16,17]}$ In addition, phosphorus also increases parathyroid cell proliferation directly ${ }^{[18]}$.

The current study finds the similar change in the calciumphosphate-Vitamin D in the CRF patients, in our population, and highlights the risk that these patients are under as further complications of such dysregulation, and the importance of regularly monitoring these parameters in our population also. These results also point towards a possible beneficial role of Vitamin D supplementation in the CRF patients. Kandula P et al in a meta-analysis of the observational studies as well as randomized controlled trials have shown improvement of biochemical endpoints in the Chronic renal failure after Vitamin D supplementation, could not find any conclusive evidence of actual clinical improvement due to lack of data, especially of randomized controlled trials in this matter ${ }^{[19]}$.

The results of the present study underlines the importance of further studies to gather more data on the abnormality in calcium phosphate and vitamin D regulation in the Chronic Renal Failure, especially in our population. The present study tries to bridge this gap to some extent but further studies including randomized controlled trial on any possible beneficial effect on Vitamin D supplementation in these patients is warranted.

\section{REFERENCES:}

1. Eknoyan G, Lameire N, Barsoum R, et al. (2004). "The burden of kidney disease: improving global outcomes". Kidney Int 66: 1310-4. doi:10.1111/j. 15231755.2004.00894.x. PMID 15458424.

2. A Martínez-Castelao; JL. Górriz; J Bover; et al. (2014). "Consensus document for the detection and management of chronic kidney disease". Nefrologia 34 (2): 24362. doi:10.3265/Nefrologia.pre2014.Feb.12455. PMID 4658201.

3. Amann K, Gross ML, London GM etal. Hyperphosphataemia - a silent killer of patients with renal failure? Nephrol Dial Transplant. 1999; 14: 2085-2087.

4. Braun J, Oldendrof M, Moshage W, Heidler R, Zeitler E, Lift F. Electron beam computed tomography in evaluation of cardiac calcifications in chronic dialysis patients. Kidney Disease 1996; 27: 394-401.

5. Amann K, Gross ML, London GM etal. Hyperphosphataemia - a silent killer of patients with renal failure? Nephrol Dial Transplant 1999; 14: 2085-2087.

6. Salary Drown A, silver J, Brewer G, Naveh Many T. Identification of AUFl as a parathyroid hormone mRNA $3^{\prime}$ - untranslated region - binding protein that determines parathyroid hormone m RNA stability. J. Biol Chen 2000; 275 : 7424 -7429 .

7. Slatopolsky E. The role of calcium, phosphate and vitamin D metabolism in the development of secondary hyperparathyroidism. Nephrol Dial Transplant 1998; 3: 3-8.

8. Silver J. Molecular mechanisms of secondary hyperparathyroidism. Nephrol Dial transplant 2000; 15 [supply 5] : 52 - 57.

9. Drueke TB. The pathogenesis gland hyperplasia in chronic renal failure? urea. Kidney Into 1995; 48: 259 - 272

10. Lesley A. Stevens, Ognjenka Djurdjev, Savannah Cardew, E. C. Cameron and Adeera Levin. Calcium, Phosphate, and Parathyroid Hormone Levels in Combination and as a Function of Dialysis Duration Predict Mortality: Evidence for the Complexity of the Association between Mineral Metabolism and Outcomes. JASN. March 2004; 15 (3): 770-779

11. GA Block, TE Hulbert-Shearon, NW Levin, FK Port. Association of serum phosphorus and calcium $\mathrm{x}$ phosphate product with mortality risk in chronic hemodialysis patients: A national study. American Journal of Kidney Diseases. 1998; 0 607-617

12. Ogo I. Egbuna,Jeremy G. Taylor,David A. Bushinsky,Martin S. Zand. Elevated calcium phosphate product after renal transplantation is a risk factor for graft failure Clinical Transplantation. 2007; 21(4): 558-566

13. Charat Thongprayoon, Wisit Cheungpasitporn, Michael A Mao, Stephen B Erickson. Calcium-phosphate product and its impact on mortality in hospitalized patients. Nephrology. January 2020; 25(1): 22-28
14. Kathleen M. Hill Gallant and David M. Spiegel. Calcium Balance in Chronic Kidney Disease. Curr Osteoporos Rep. 2017; 15(3): 214-221

15. Abeer Yasin, Daisy Liu, Luan Chau, Joaquín Madrenas \& Guido Filler Fibroblast growth factor-23 and calcium phosphate product in young chronic kidney disease patients: a cross-sectional study BMC Nephrology. 2013; Volume 14

16. Almaden Y, Hernandez A, Torregrosa V etal. High phosphate level directly stimulates parathyroid hormone secretion and synthesis by human parathyroid tissue in vitro. J Am Soc Nephrol 1998; 9: 1845-1852.

17. Slatopolsky E, Finch J; Denda M etal. Phosphate restriction prevents parathyroid cell growth in uremic rats. High phosphate directly stimulates PTH secretion in vitro. J Coin Invest 1996; 97: 2534 - 2540.

18. Roussanne MC, Lieberherr M, Souberbielle JC, Sarfati E, Drueke T, Bourdeau A. Human parathyroid cell proliferation in response to calcium, NPS R - 467, calcitriol and phosphate. Eur J Invest 2001; 31:610-616.

19. Praveen Kandula, Mirela Dobre, Jesse D. Schold, Martin J. Schreiber, Rajnish Mehrotra and Sankar D. Navaneethan. Vitamin D Supplementation in Chronic Kidney Disease: A Systematic Review and Meta-Analysis of Observational Studies and Randomized Controlled Trials. CJASN January $2011 ; 6(1): 50-62$ 